\title{
Neuropsychiatric Symptoms and Mortality Among Patients With Mild Cognitive Impairment and Dementia Due to Alzheimer's Disease
}

\section{Mei-Feng Huang}

Kaohsiung Medical University College of Medicine

Wei-Ju Lee

Taichung Veterans General Hospital

\section{Yi-Chun Yeh}

Kaohsiung Medical University

Yung-Shuan Lin

National Yang-Ming University

\section{Hsiu-Fen Lin}

Kaohsiung Medical University

\section{Shuu-Jiun Wang}

National Yang-Ming University

Yi-Hsin Yang

National Health Research Institutes

Cheng-Sheng Chen ( $\nabla$ sheng@kmu.edu.tw)

Kaohsiung Medical University

Jong-Ling Fuh

National Yang-Ming University

\section{Research}

Keywords: Mortality, neuropsychiatric symptoms, Alzheimer's disease, mild cognitive impairment

Posted Date: October 1st, 2020

DOI: https://doi.org/10.21203/rs.3.rs-83308/v1

License: (c) (i) This work is licensed under a Creative Commons Attribution 4.0 International License. Read Full License

Version of Record: A version of this preprint was published at Journal of the Formosan Medical Association on December 1st, 2021. See the published version at 
https://doi.org/10.1016/j.jfma.2021.12.004. 


\section{Abstract}

\section{Background}

Neuropsychiatric symptoms (NPS) could increase mortality risk in people with dementia due to Alzheimer's disease (AD). However, whether NPS affects mortality risk in people with mild cognitive impairment $(\mathrm{MCl})$ and whether any specific syndrome of NPS influences this risk are still unclear.

\section{Methods}

In total, 984 participants with dementia due to $A D, 338$ with $\mathrm{MCl}$, and 365 controls were enrolled. Over a mean of 5-year follow-up, cause of death data were obtained from the Ministry of Health and Welfare in Taiwan. NPS were assessed using Neuropsychiatric Inventory Questionnaire (NPI-Q), and psychosis, mood, and frontal domain scores were determined. Survival analyses were conducted to determine the hazard ratio (HR) of death.

\section{Results}

In controlled analyses, HR of death for AD was 2.19 (95\% confidence interval [CI] $=1.29-3.71$ ) compared with the control group, whereas no statistical significance was noted for the $\mathrm{MCl}$ group. A high NPI-Q score (above the median score) increased mortality risk for both the $\mathrm{MCl}$ and $\mathrm{AD}$ groups, with $\mathrm{HRs}$ of 2.32 $(95 \% \mathrm{Cl}=1.07-5.03)$ and $2.60(95 \% \mathrm{Cl}=1.51-4.47)$, respectively. Among NPI-Q domain scores, only high mood domain, but not psychosis or frontal domain, scores increased death risk for both the $\mathrm{MCl}(\mathrm{HR}=$ $2.89,95 \% \mathrm{Cl}=1.00-8.51)$ and $\mathrm{AD}(\mathrm{HR}=2.59,95 \% \mathrm{Cl}=1.47-4.55)$ groups.

\section{Conclusions}

Mortality risk is high for patients with AD. Not only for AD, patients with $\mathrm{MCl}$ presenting with NPS, particularly mood symptoms, have high death risk.

\section{Background}

Dementia due to Alzheimer's disease (AD) is the major leading cause of death worldwide [1], with an estimated survival period of 3-8 years from diagnosis to death depending on age at onset [2]. Many people in the early stages of $A D$ are unaware of their condition and are not identified to have $A D$ by health care authorities. Mild cognitive impairment $(\mathrm{MCl})$ is identified as a clinical entity that represents a prodromal stage of dementia. Patients with $\mathrm{MCl}$ present cognitive impairment that is less severe and does not affect independency in activities of daily living. Some patients with $\mathrm{MCl}$ may develop dementia in the following years [3]; however, others may remain in the $\mathrm{MCl}$ stage or even return to cognitive normalcy [4]. Studies investigating clinical outcomes have suggested that patients with $\mathrm{MCl}$ have a decreased life span [5-9]. 
Several factors affect mortality in patients with dementia, including behavioral disturbance, namely neuropsychiatric symptoms (NPS) [10]. NPS, including psychosis and mood and behavior symptoms, are core features of $A D$ [11]. Usually, they emerge primarily in people with late-stage disease, but these symptoms manifest commonly in early stages and prodromal phases, such as $\mathrm{MCl}$ [12]. However, thus far, no study had investigated the effect of NPS on mortality in patients with $\mathrm{MCl}$.

NPS are heterogeneous and are not a unitary condition and hence should be regarded as groups of symptoms; three to five groups of NPS have been identified [13-18]. Regrouping NPS into syndromes has been supported by several underpinning neurobiology findings and outcomes across each group of NPS $[14,19,20]$. However, the prognosis of each syndrome of NPS has not been clearly studied. Each group of NPS could lead to various outcomes of cognitive disorder, including mortality.

We adapted a prospective design to study mortality in patients with $A D$ or $\mathrm{MCl}$. The aims of this study were to investigate the hazard risk of mortality in patients with $A D$ or $\mathrm{MCl}$ in comparison with cognitively normal subjects. Next, we investigated the mortality risk associated with NPS in patients with AD or MCI. Furthermore, we examined the associations between the domains of NPS and mortality risk in AD and $\mathrm{MCl}$. We hypothesized that NPS confer a mortality risk to patients with $\mathrm{AD}$ or $\mathrm{MCl}$. Certain domains of NPS have a higher mortality risk than others.

\section{Methods}

\section{Participants}

Patients with newly diagnosed $A D$ or $\mathrm{MCl}$ were recruited from three teaching hospitals. The inclusion criteria of $A D$ or $\mathrm{MCl}$ were (1) age of 60-90 years, (2) diagnosis of probable $A D$ as described by the National Institute on Aging-Alzheimer's Association [21] or MCl according to the revised consensus criteria from 2004 [22], and (3) at least one knowledgeable caregiver who could report observations of the patient's behaviors. The exclusion criteria were (1) other major neurological illnesses (e.g., stroke, Parkinson disease, epilepsy, and traumatic head injury) or (2) comorbid with other types of dementia. A control group was enrolled from outpatient clinics. Participants were enrolled from July 2012 to January 2019. Completed written consent forms were obtained from all study patients and their caregivers before study initiation. The protocol of the study was approved by the institutional review boards of three hospitals.

\section{Mortality data}

All-cause mortality was defined as the date of disenrollment due to death, as per the records of the Taiwan Ministry of Health and Welfare, which maintains a national database of all citizens' coded death certificates. The years of follow-up for each individual were calculated from the baseline to the date of death or the end of the follow-up period on May 31, 2019, whichever occurred earlier. The causes of death were coded according to the 10th Revision of International Classification of Diseases (ICD-10). Deaths were classified as all-cause, dementia and senile syndrome (ICD-10 codes F00-G30), cancer (ICD-10 
codes C00-D49), cardiovascular disease (ICD-10 codes 100-199), and respiratory disease (ICD-10 codes J00-J99).

\section{Assessments}

All participants underwent a standardized assessment, including a clinical interview, cognitive and behavioral assessment, laboratory tests, and brain imaging study. Cognitive function was assessed using Mini-Mental State Examination (MMSE) [23], and dementia staging was determined according to Clinical Dementia Rating scores [24]. Physical Self-Maintenance Scale (PSMS) was used to assess disability severity of activities of daily living (ADL). PSMS is a six-item questionnaire that assesses the following tasks: toilet, feeding, dressing, grooming, physical ambulation, and bathing. A 5-point scale for responses ranges from total independence to total dependence [25]. The possible score ranges from 0 to 24 , and a high score is indicative of poor functioning.

The presence and severity of NPS were assessed using Neuropsychiatric Inventory Questionnaire (NPI-Q) [26]. The $12 \mathrm{NPI-Q}$ items were delusions, hallucinations, agitation/aggression, depression/dysphoria, anxiety, apathy/indifference, euphoria/elation, irritability/lability, disinhibition and aberrant motor activity, eating habit change, and sleep problems. A score of 0 indicates no symptom, whereas scores of 1-3 (with higher scores indicating more severity) indicate the presence of symptoms. Three symptom groups of NPI-Q were derived as follows: mood (indicated by anxiety, apathy, and dysphoria items), psychosis (irritability/lability, delusions, hallucinations, and agitation/aggression), and frontal symptoms (euphoria and disinhibition) [27]. Item scores of each symptom domain were computed to generate mood, psychosis, and frontal subscores.

\section{Controlled variables}

Self-administered questionnaires for study participants or the family of patients with $A D$ were used to collect data on age, sex, education year, and medical history, including hypertension, diabetes mellitus, stroke, hyperlipidemia, and cardiovascular disorders. Medical diseases were considered present based on a self-report of physician-diagnosed diseases or medication use. At least one of APOE e4 alleles was also treated as covariate.

\section{Statistics analysis}

Continuous variables are expressed as mean \pm standard deviation (SD) and categorical variables as percentages. The significance of differences in continuous variables across diagnoses was examined using an independent $t$ test or one-way analysis of variance, as appropriate. The difference in the distribution of categorical variables was examined using a chi-square test. We first derived the survival curve of the three diagnostic groups by using the Kaplan-Meier survival analysis with log-rank tests. Then, Cox proportional hazard regression analysis was performed to examine mortality risk. Covariates included age, sex, education, medical diseases (cardiovascular diseases, hypertension, diabetes, stroke, and dyslipidemia), and MMSE and ADL total scores at baseline. Three Cox proportional hazard 
regression models were used. Model I was used to investigate the cognitive diagnosis (controls, $\mathrm{MCl}$, and AD). Model II was to study diagnosis/NPS variables, which included control, $\mathrm{MCl}$ with low score of NPI-Q (MCl/NPS-), MCl with high score of NPI-Q (MCl/NPS+), AD with low score of NPI-Q (AD/NPS-), and AD with high score of NPI-Q (MCl/NPS+). Finally, Model III was used to investigate the mortality risk of diagnosis/NPI domains (mood, psychosis, and frontal). High and low total scores of NPI-Q or subscores of NPI-Q domains were defined based on the cutoff of median scores among all patients with AD or MCI. Multicollinearity among variables was detected by examining the correlation matrix of correlation coefficients, assuming that no values were $>0.7$ [28]. The level of significance was set at $p<0.05$ (twotailed).

\section{Results}

At baseline, 984 patients with AD, 338 patients with $\mathrm{MCl}$, and 365 controls were identified and included in this study. Demographic and clinical data are shown in Table 1. Among patients with AD, $50 \%$ were women, and the mean (SD) age was 78.2 (7.9) years; among patients with $\mathrm{MCl}, 49.7 \%$ were women, and the mean (SD) age was 72.4 (78.8) years. Mean (SD) follow-up time was 5.1 (2.6) years for people with $\mathrm{AD}, 4.0$ (2.0) for people with $\mathrm{MCl}$, and 4.4 (2.2) for controls.

In total, 291 participants $(17.2 \%)$ died during the follow-up period, and 248 patients had AD $(248 / 983=$ $25.2 \%), 22$ had $\mathrm{MCl}(22 / 340=6.5 \%)$, and 21 were controls $(21 / 364=5.8 \%)$. The incidence rates of death per 1000 person-years were 50.5 for $A D, 12.9$ for $\mathrm{MCl}$, and 11.5 for control. The mean survival period was 5.5 years for $A D$ and 6.4 years for $\mathrm{MCl}$ using Kaplan-Meier survival analysis with log-rank tests.

Significant differences were observed between $A D$ and $M C l$ groups $(p<0.001)$ and between $A D$ and control groups $(p<0.001)$, whereas no differences were observed between $\mathrm{MCl}$ and control groups $(p=$ 0.336). Causes of death across the three groups are listed in Table 1. The most common cause of death in the AD group was cardiovascular disease, followed by respiratory diseases and cancer. The order of causes of death in the $A D$ group differed from that in the $\mathrm{MCl}$ and control groups.

In the Cox proportional hazard regression models controlled for age, sex, education, medical diseases (hypertension, diabetes, cardiovascular disease, hyperlipidemia, and stroke), and total scores of MMSE and ADL (model I), the hazard ratio (HR) of mortality was 2.14 (95\% confidence interval $[\mathrm{Cl}]=1.26-3.64$, $\mathrm{p}=0.005)$ for the $\mathrm{AD}$ group and $1.16(95 \% \mathrm{Cl}=0.60-2.24, \mathrm{p}=0.66$ for the $\mathrm{MCl}$ group compared with the control group (Fig. 1).

Cutoff of the median score of NPI-Q was 3/4, and accordingly, the total score of NPI-Q was divided into high (total score $\geq 4$ ) and low (total score $\leq 3$ ) scores. In the Cox proportional hazard regression model (model II) with the same covariates as that in model I, compared with controls, the HRs were $0.75(95 \% \mathrm{Cl}$ $=0.33-1.73, \mathrm{p}<0.50)$ for MCl/NPS-, $2.30(95 \% \mathrm{Cl}=1.06-5.01, \mathrm{p}=0.035)$ for $\mathrm{MCl} / \mathrm{NPS}+, 1.74(95 \% \mathrm{Cl}=$ $1.00-3.04, p=0.05)$ for AD/NPS-, and $2.58(95 \% \mathrm{Cl}=1.49-4.46, \mathrm{p}=0.001)$ for AD/NPS+ (Fig. 2). The mean survival duration was 5.3 years for AD/NPS+, 5.9 years for MCl/NPS+, and 5.9 years for AD/NPS-, as revealed by Kaplan-Meier survival analysis with log-rank tests. On adding a variable of defined daily 
dose (DDD) of antipsychotics [29] to model II, the results revealed that the mortality risk of each group did not alter significantly, and DDD of antipsychotics did not increase mortality risk $(\mathrm{HR}=2.78,95 \% \mathrm{Cl}=$ $0.66-11.69, p=0.16)$.

We divided groups according to median subscores of the domains of NPI-Q, which are mood, psychosis, and frontal domains. High scores of mood, psychosis, and frontal domains were $\geq 2, \geq 2$, and $\geq 1$, respectively. Subsequently, three variables were created, namely diagnosis/mood (control, $\mathrm{MCl} / \mathrm{mood}-$, $\mathrm{MCl} / \mathrm{mood}+, \mathrm{AD} / \mathrm{mood}-$, and $\mathrm{AD} / \mathrm{mood}+$ ), diagnosis/psychosis (control, $\mathrm{MCl} /$ psychosis-, $\mathrm{MCl} /$ psychosis+, $\mathrm{AD} /$ psychosis-, and $\mathrm{AD} /$ psychosis+), and diagnosis/frontal (control, $\mathrm{MCl} /$ frontal-, $\mathrm{MCl} /$ frontal+, $A D /$ frontal-, and $A D /$ frontal+). A Cox regression model (model III) was created using model I covariates to examine the mortality risks of the aforementioned three variables, and the results showed that only $\mathrm{MCl} / \mathrm{mood}+(\mathrm{HR}=3.00,95 \% \mathrm{Cl}=1.00-8.83, \mathrm{p}=0.046), \mathrm{AD} / \operatorname{mood}-(\mathrm{HR}=2.37,95 \% \mathrm{Cl}=1.29-$ $4.36, p=0.005)$, and $A D /$ mood $+(H R=2.72,95 \% \mathrm{Cl}=1.54-4.79, p=0.001)$ conferred mortality risks. Table 2 summaries the results of models I, II, and III.

\section{Discussion}

The main findings of this study are as follows: (1) an increased mortality rate was observed in elderly patients with $A D$, with HR of 2.19 after controlling for covariates, including cognitive function and disability; (2) the incidence rates of death per 1000 person-years were 50.5 and 12.9 for the AD and $\mathrm{MCl}$ groups, respectively, and the mean survival durations were 5.5 and 6.4 years for the $A D$ and $\mathrm{MCl}$ groups, respectively; (3) NPS increased death risk in both the MCl and AD groups by 2.32- and 2.60-fold, respectively; and (4) among all the domains of NPS, mood domain, but not psychosis or frontal domain, increased mortality risk.

The mean estimate of survival in AD was 5.5 years in this study conducted in Asia. Overall, shortened life expectancy has been noted after first diagnosis at different ages and ranged from approximately 10 years at onset of 60 years to approximately 3 years at onset of 95 years [2]. Our finding of 5.5 years for $A D$ in this population with a mean age of 78 years was compatible with the aforementioned observation. The literature has demonstrated several risk factors for mortality in AD, including age, sex, baseline cognitive function, and functional disabilities [30,31], which were also noted in our study. Contrary to the general population, with cancer being the most common cause of death, our findings suggested that patients with dementia commonly die of cardiovascular or respiratory diseases, which is in line with a previous finding [32].

Mortality risk in $\mathrm{MCl}$ did not reach statistical difference in this study. Various definitions of $\mathrm{MCl}$ have been proposed. For instance, Peterson $\mathrm{MCl}$ Criteria emphasize the presence of subjective memory complaints and subclinical objective memory performance in the context of relatively intact everyday functioning [33]. Recent consensus criteria for mild neurocognitive disorder have been included in Diagnostic and Statistical Manual of Mental Disorders, Fifth Edition (DSM-5) [34], which specifies a modest decline in one or more cognitive domains but cognitive deficits that do not affect independence in everyday 
activities. Increased effort, compensatory strategies, or accommodation may be required to stay independent. In comparison, DSM-5 criteria emphasize objective cognitive impairment and subclinical functional impairment, whereas the Peterson criteria do not. DSM-5 $\mathrm{MCl}$ allows for greater compromise in functional independence than Peterson criteria do, indicating a severe form of $\mathrm{MCl}$ [35]. One study comparing the mortality risk of $\mathrm{MCl}$ using DSM-5 and Peterson criteria found that mortality risk was higher in DSM-5-diagnosed $\mathrm{MCl}$ than in Peterson criteria-diagnosed $\mathrm{MCl}$ [7]. As Peterson criteria are considered heterogeneous, a considerable proportion of patients do not develop dementia or may even return to normal cognition [36]. In this study, the case definition of $\mathrm{MCl}$ was according to Peterson $\mathrm{MCl}$ criteria, which is possibly one of the reasons for the low mortality rate in $\mathrm{MCl}$.

However, we found shortened survival in the MCl group if NPS were considered. Mean survival period of 5.9 years in patients with $\mathrm{MCl}$ with significant NPS was similar to that of patients with AD without significant NPS. The relationship between NPS and mortality is complex. Our analyses were adjusted for age, sex, education, APOE, other medical conditions, baseline cognition, and function status, and even then, NPS affected mortality in both the AD and $\mathrm{MCl}$ groups. The findings indicate that factors beyond covariates mediate the relationships. A new phenotype, namely mild behavioral impairment (MBI), was proposed and defined as late-onset NPS in the context of predementia [37]. Elderly people with coexisting $\mathrm{MBI}$ and $\mathrm{MCl}$ have a higher risk of developing dementia than those with $\mathrm{MCl}$ alone [38] [39]. Furthermore, biomarker studies have suggested that patients with MBI share similar genetic profiles, brain betaamyloid imaging, and plasma neurofilament light with those with AD [40-42]. In addition to conversion to $A D$, our findings highlight the clinical significance of NPS in MCl in terms of mortality and support the $\mathrm{MBI}$ concept, which allows for early identification and facilitates new possibilities for therapeutic intervention.

In addition to factors related to cognitive disorders per se, studies have suggested that antipsychotic treatment is one of the possible risk factors [43]. In our study, we added the precise variable of DDD of antipsychotics [29] to the survival analysis. DDD is used for calculating the assumed average maintenance dose per day for a drug used for its main indication. Using DDD allowed us to combine different antipsychotics to compare their mortality risk. However, the analysis did not reveal the mortality risk of DDD of antipsychotics ( $\mathrm{HR}=2.78,95 \% \mathrm{Cl}=0.66-11.69, \mathrm{p}=0.16)$. However, the risk of antipsychotic use in treating NPS for either AD or MCl could not be excluded as the DDD of antipsychotics was only at baseline and not over this study period.

An intriguing result was that the mood domain, but not psychosis or frontal domain, was associated with mortality. Mood domain of NPI-Q comprise anxiety, apathy, and dysphoria. Late-life depression could increase dementia risk [44,45], and mood dysregulation is often the indicator of neurodegenerative diseases and progressive cognitive change [46]. Studies have suggested that affective symptoms and apathy are associated with early death in $\operatorname{AD}[47,48]$. Depression itself increases death risk [49]. Depression or apathy in dementia could aggravate failure to thrive and difficulty to manage chronic disease and may lead to social isolation $[50,51]$. Therefore, these mood symptoms could accelerate cognitive and functional progression and lead to increased mortality risk. No association was noted 
between psychosis and survival time in this study, which is contrary to the finding of a study in community-dwelling elderly people [52]. A possible explanation for the disparity is the study population. This study was hospital-based; thus, treatment for psychosis was provided more actively than in the community. However, further studies are required to explain this discrepancy.

\section{Limitations}

Some limitations merit discussion. First, in this study, only baseline NPS were identified, but NPS may change over time. A further study using the NPS change trend will be beneficial. Second, as study participants were enrolled from teaching hospitals, the findings need to be extrapolated cautiously to other populations. Third, although DDD is a delicate measure of antipsychotics dose, we could not exclude the nonlinear association between drug dose and mortality risk. Finally, studies with large study samples are necessary in future to confirm the findings.

\section{Conclusion}

In conclusion, in this longitudinal study, high mortality risk was noted in patients with $A D$ or $\mathrm{MCl}$ with coexisting NPS. NPS increased death risk in both the MCl and AD groups by 2.32-and 2.60-fold, respectively. Furthermore, the mood domain of NPS increased death risk.

\section{Abbreviations}

Neuropsychiatric symptoms (NPS)

Alzheimer's disease (AD)

mild cognitive impairment (MCl)

Neuropsychiatric Inventory Questionnaire (NPI-Q)

hazard ratio $(\mathrm{HR})$

International Classification of Diseases (ICD-10)

Mini-Mental State Examination (MMSE)

Physical Self-Maintenance Scale (PSMS)

activities of daily living (ADL)

standard deviation (SD)

defined daily dose (DDD)

Diagnostic and Statistical Manual of Mental Disorders, Fifth Edition (DSM-5) 
mild behavioral impairment (MBI).

\section{Declarations}

\section{Ethics approval and consent to participate:}

Completed written consent forms were obtained from all study patients and their caregivers before study initiation. The protocol of the study was approved by the institutional review boards of three hospitals.

\section{Consent for publication}

Not applicable

\section{Availability of data and materials}

The datasets used and/or analysed during the current study are available from the corresponding author on reasonable request.

\section{Competing interests}

The authors declare that they have no competing interests

\section{Funding}

This research did not receive any specific grant from funding agencies in the public, commercial, or notfor-profit sectors.

\section{Authors' contributions}

WJL, SJW and JLF designed the study. YSL, HFL, and JLF make contributions to acquisition and interpretation of data. MFH, YCY, YHY and CSC analyzed and interpreted the data. MFH and CSC was a major contributor in writing the manuscript. All authors read and approved the final manuscript.

\section{Acknowledgements}

The study was supported by grants from the Academia Sinica of Taiwan (AS-BD-108-2), the Ministry of Science and Technology of Taiwan (MOST 106-2314-B-037-041-MY3, 106-3114-Y-043-022, 107-2221-E075-006-, 108-2321-B-075-001-, 109-2314B-075-052-MY2), Taipei Veterans General Hospital ( V107C032, V108C-113, V108D43-002-MY2-1), Kaohsiung Medical University Hospital (KMUH 101-1M57) and the Brain Research Center, National Yang-Ming University from The Featured Areas Research Center Program within the framework of the Higher Education Sprout Project by the Ministry of Education (MOE) in Taiwan.

\section{References}


1. 2020 Alzheimer's disease facts and figures. Alzheimers Dement 2020.

2. Brookmeyer R, Corrada MM, Curriero FC, Kawas C: Survival following a diagnosis of Alzheimer disease. Arch Neurol 2002, 59(11):1764-1767.

3. Petersen RC: Aging, mild cognitive impairment, and Alzheimer's disease. Neurol Clin 2000, 18(4):789806.

4. Ganguli M, Snitz BE, Saxton JA, Chang CC, Lee CW, Vander Bilt J, Hughes TF, Loewenstein DA, Unverzagt FW, Petersen RC: Outcomes of mild cognitive impairment by definition: a population study. Arch Neurol 2011, 68(6):761-767.

5. Vassilaki M, Cha RH, Aakre JA, Therneau TM, Geda YE, Mielke MM, Knopman DS, Petersen RC, Roberts RO: Mortality in mild cognitive impairment varies by subtype, sex, and lifestyle factors: the Mayo Clinic Study of Aging. J Alzheimers Dis 2015, 45(4):1237-1245.

6. Yu L, Boyle PA, Leurgans SE, Wilson RS, Bennett DA, Buchman AS: Incident Mobility Disability, Mild Cognitive Impairment, and Mortality in Community-Dwelling Older Adults. Neuroepidemiology 2019, 53(1-2):55-62.

7. Santabarbara J, Gracia-Garcia P, Pirez G, Lopez-Anton R, De La Camara C, Ventura T, Perez-Sastre M, Lobo E, Saz P, Marcos G et al: Mortality in Mild Cognitive Impairment Diagnosed with DSM-5 Criteria and with Petersen's Criteria: A 17-Year Follow-Up in a Community Study. Am J Geriatr Psychiatry 2016, 24(11):977-986.

8. Contador I, Bermejo-Pareja F, Mitchell AJ, Trincado R, Villarejo A, Sanchez-Ferro A, Benito-Leon J: Cause of death in mild cognitive impairment: a prospective study (NEDICES). Eur J Neuro/ 2014, 21(2):253-e259.

9. Paddick SM, Kisoli A, Dotchin CL, Gray WK, Chaote P, Longdon A, Walker RW: Mortality rates in community-dwelling Tanzanians with dementia and mild cognitive impairment: a 4-year follow-up study. Age Ageing 2015, 44(4):636-641.

10. Bransvik V, Granvik E, Minthon L, Nordstrom P, Nagga K: Mortality in patients with behavioural and psychological symptoms of dementia: a registry-based study. Aging Ment Health 2020:1-9.

11. Spalletta G, Baldinetti F, Buccione I, Fadda L, Perri R, Scalmana S, Serra L, Caltagirone C: Cognition and behaviour are independent and heterogeneous dimensions in Alzheimer's disease. Journal of Neurology 2004, 251(6):688-695.

12. Taragano FE, Allegri RF, Lyketsos C: Mild behavioral impairment: A prodromal stage of dementia. Dement Neuropsychol 2008, 2(4):256-260.

13. Aalten P, Verhey FR, Boziki M, Bullock R, Byrne EJ, Camus V, Caputo M, Collins D, De Deyn PP, Elina K et al: Neuropsychiatric syndromes in dementia. Results from the European Alzheimer Disease Consortium: part I. Dementia and Geriatric Cognitive Disorders 2007, 24(6):457-463.

14. Cummings JL, McRae T, Zhang R: Effects of donepezil on neuropsychiatric symptoms in patients with dementia and severe behavioral disorders. Am J Geriatr Psychiatry 2006, 14(7):605-612.

15. Fuh JL, Lam L, Hirono N, Senanarong V, Cummings JL: Neuropsychiatric inventory workshop: behavioral and psychologic symptoms of dementia in Asia. Alzheimer Disease \& Associated 
Disorders 2006, 20(4):314-317.

16. Mirakhur A, Craig D, Hart DJ, McLIroy SP, Passmore AP: Behavioural and psychological syndromes in Alzheimer's disease. International Journal of Geriatric Psychiatry 2004, 19(11):1035-1039.

17. Starr JM, Lonie J: Relationship between behavioural and psychological symptoms of dementia and cognition in Alzheimer's disease. Dementia and Geriatric Cognitive Disorders 2007, 24(5):343-347.

18. Chen CS, Ouyang P, Yeh YC, Lai CL, Liu CK, Yen CF, Ko CH, Yen JY, Liu GC, Juo SH: Apolipoprotein E polymorphism and behavioral and psychological symptoms of dementia in patients with Alzheimer disease. Alzheimer Dis Assoc Disord 2012, 26(2):135-139.

19. Robert PH, Verhey FR, Byrne EJ, Hurt C, De Deyn PP, Nobili F, Riello R, Rodriguez G, Frisoni GB, Tsolaki $\mathrm{M}$ et al: Grouping for behavioral and psychological symptoms in dementia: clinical and biological aspects. Consensus paper of the European Alzheimer disease consortium. Eur Psychiatry 2005, 20(7):490-496.

20. Gauthier S, Wirth Y, Mobius HJ: Effects of memantine on behavioural symptoms in Alzheimer's disease patients: an analysis of the Neuropsychiatric Inventory (NPI) data of two randomised, controlled studies. Int J Geriatr Psychiatry 2005, 20(5):459-464.

21. McKhann GM, Knopman DS, Chertkow H, Hyman BT, Jack CR, Jr., Kawas CH, Klunk WE, Koroshetz WJ, Manly JJ, Mayeux R et al: The diagnosis of dementia due to Alzheimer's disease: recommendations from the National Institute on Aging-Alzheimer's Association workgroups on diagnostic guidelines for Alzheimer's disease. Alzheimers Dement 2011, 7(3):263-269.

22. Petersen RC: Mild cognitive impairment as a diagnostic entity. J Intern Med 2004, 256(3):183-194.

23. Folstein MF, Folstein SE, McHugh PR: "Mini-mental state". A practical method for grading the cognitive state of patients for the clinician. J Psychiatr Res 1975, 12(3):189-198.

24. Lin K-N, Liu HC: Clinical dementia rating (CDR), Chinese version, vol. 12; 2003.

25. Lawton MP, Brody EM: Assessment of older people: self-maintaining and instrumental activities of daily living. Gerontologiest 1969, 9(3):179-186.

26. Kaufer DI, Cummings JL, Ketchel P, Smith V, MacMillan A, Shelley T, Lopez OL, DeKosky ST: Validation of the NPI-Q, a brief clinical form of the Neuropsychiatric Inventory. J Neuropsychiatry Clin Neurosci 2000, 12(2):233-239.

27. Johnson DK, Watts AS, Chapin BA, Anderson R, Burns JM: Neuropsychiatric profiles in dementia. Alzheimer Dis Assoc Disord 2011, 25(4):326-332.

28. Dormann CF, Elith J, Bacher S, Buchmann C, Carl G, Carre G, Marquez J, R. C., Gruber B, Lafourcade B, Leitao PJ et al: Collinearity: a review of methods to deal with it and a simulation study evaluating their performance. Ecography 2013, 36(1):27-46.

29. Leucht S, Samara M, Heres S, Davis JM: Dose Equivalents for Antipsychotic Drugs: The DDD Method. Schizophr Bull 2016, 42 Suppl 1:S90-94.

30. Brodaty H, Seeher K, Gibson L: Dementia time to death: a systematic literature review on survival time and years of life lost in people with dementia. Int Psychogeriatr 2012, 24(7):1034-1045. 
31. Todd S, Barr S, Roberts M, Passmore AP: Survival in dementia and predictors of mortality: a review. Int J Geriatr Psychiatry 2013, 28(11):1109-1124.

32. Brunnstrom HR, Englund EM: Cause of death in patients with dementia disorders. Eur J Neuro/ 2009, 16(4):488-492.

33. Petersen RC, Smith GE, Waring SC, Ivnik RJ, Tangalos EG, Kokmen E: Mild cognitive impairment: clinical characterization and outcome. Arch Neurol 1999, 56(3):303-308.

34. Sachdev PS, Blacker D, Blazer DG, Ganguli M, Jeste DV, Paulsen JS, Petersen RC: Classifying neurocognitive disorders: the DSM-5 approach. Nat Rev Neurol 2014, 10(11):634-642.

35. Lopez-Anton R, Santabarbara J, De-la-Camara C, Gracia-Garcia P, Lobo E, Marcos G, Pirez G, Saz P, Haro JM, Rodriguez-Manas $L$ et al: Mild cognitive impairment diagnosed with the new DSM-5 criteria: prevalence and associations with non-cognitive psychopathology. Acta Psychiatr Scand 2015, 131(1):29-39.

36. Kaduszkiewicz H, Eisele M, Wiese B, Prokein J, Luppa M, Luck T, Jessen F, Bickel H, Mosch E, Pentzek $M$ et al: Prognosis of mild cognitive impairment in general practice: results of the German AgeCoDe study. Ann Fam Med 2014, 12(2):158-165.

37. Ismail Z, Smith EE, Geda Y, Sultzer D, Brodaty H, Smith G, Aguera-Ortiz L, Sweet R, Miller D, Lyketsos $\mathrm{CG}$ et al: Neuropsychiatric symptoms as early manifestations of emergent dementia: Provisional diagnostic criteria for mild behavioral impairment. Alzheimers Dement 2016, 12(2):195-202.

38. Taragano FE, Allegri RF, Krupitzki H, Sarasola DR, Serrano CM, Lon L, Lyketsos CG: Mild behavioral impairment and risk of dementia: a prospective cohort study of $\mathbf{3 5 8}$ patients. J Clin Psychiatry 2009, 70(4):584-592.

39. Taragano FE, Allegri RF, Heisecke SL, Martelli MI, Feldman ML, Sanchez V, Garcia VA, Tufro G, Castro DM, Leguizamon PP et al: Risk of Conversion to Dementia in a Mild Behavioral Impairment Group Compared to a Psychiatric Group and to a Mild Cognitive Impairment Group. J Alzheimers Dis 2018, 62(1):227-238.

40. Lussier FZ, Pascoal TA, Chamoun M, Therriault J, Tissot C, Savard M, Kang MS, Mathotaarachchi S, Benedet AL, Parsons $\mathrm{M}$ et al: Mild behavioral impairment is associated with beta-amyloid but not tau or neurodegeneration in cognitively intact elderly individuals. Alzheimers Dement 2020, 16(1):192199.

41. Andrews SJ, Ismail Z, Anstey KJ, Mortby M: Association of Alzheimer's genetic loci with mild behavioral impairment. Am J Med Genet B Neuropsychiatr Genet 2018, 177(8):727-735.

42. Naude JP, Gill S, Hu S, McGirr A, Forkert ND, Monchi O, Stys PK, Smith EE, Ismail Z, Alzheimer's Disease Neuroimaging I: Plasma Neurofilament Light: A Marker of Neurodegeneration in Mild Behavioral Impairment. J Alzheimers Dis 2020.

43. Ballard C, Creese B, Corbett A, Aarsland D: Atypical antipsychotics for the treatment of behavioral and psychological symptoms in dementia, with a particular focus on longer term outcomes and mortality. Expert Opin Drug Saf 2011, 10(1):35-43. 
44. Butters MA, Becker JT, Nebes RD, Zmuda MD, Mulsant BH, Pollock BG, Reynolds CF, 3rd: Changes in cognitive functioning following treatment of late-life depression. Am J Psychiatry 2000, 157(12):1949-1954.

45. Devanand DP, Sano M, Tang MX, Taylor S, Gurland BJ, Wilder D, Stern Y, Mayeux R: Depressed mood and the incidence of Alzheimer's disease in the elderly living in the community. Arch Gen Psychiatry 1996, 53(2):175-182.

46. Ismail Z, Gatchel J, Bateman DR, Barcelos-Ferreira R, Cantillon M, Jaeger J, Donovan NJ, Mortby ME: Affective and emotional dysregulation as predementia risk markers: exploring the mild behavioral impairment symptoms of depression, anxiety, irritability, and euphoria. Int Psychogeriatr 2018, 30(2):185-196.

47. Vilalta-Franch J, Calvo-Perxas L, Garre-Olmo J, Turro-Garriga O, Lopez-Pousa S: Apathy syndrome in Alzheimer's disease epidemiology: prevalence, incidence, persistence, and risk and mortality factors. J Alzheimers Dis 2013, 33(2):535-543.

48. Lavretsky H, Zheng L, Weiner MW, Mungas D, Reed B, Kramer JH, Jagust W, Chui H, Mack WJ: Association of depressed mood and mortality in older adults with and without cognitive impairment in a prospective naturalistic study. Am J Psychiatry 2010, 167(5):589-597.

49. Mehta KM, Yaffe K, Langa KM, Sands L, Whooley MA, Covinsky KE: Additive effects of cognitive function and depressive symptoms on mortality in elderly community-living adults. J Gerontol A Biol Sci Med Sci 2003, 58(5):M461-467.

50. Katz IR, DiFilippo S: Neuropsychiatric aspects of failure to thrive in late life. Clin Geriatr Med 1997, 13(4):623-638.

51. Palmer RM: 'Failure to thrive' in the elderly: diagnosis and management. Geriatrics 1990, 45(9):47-50, 53-45.

52. Peters ME, Schwartz S, Han D, Rabins PV, Steinberg M, Tschanz JT, Lyketsos CG: Neuropsychiatric symptoms as predictors of progression to severe Alzheimer's dementia and death: the Cache County Dementia Progression Study. Am J Psychiatry 2015, 172(5):460-465.

\section{Tables}

Table 1 Demographic and clinical data 


\begin{tabular}{|c|c|c|c|c|c|}
\hline & $\begin{array}{l}\text { Controls } \\
(\mathrm{N}=365)\end{array}$ & $\begin{array}{l}\mathrm{MCl} \\
(\mathrm{N}=338)\end{array}$ & $\begin{array}{l}A D \\
(N=984)\end{array}$ & $\begin{array}{l}\text { Total } \\
(\mathrm{N}=1687)\end{array}$ & Statistics \\
\hline \multicolumn{6}{|l|}{ Sex } \\
\hline Male & $161(44.4 \%)$ & $172(50.3 \%)$ & 491 (50.0\%) & 824 (48.8\%) & $P=0.16$ \\
\hline Female & 203 (55.6\%) & 168 (49.7\%) & 492 (50.0\%) & 863 (51.2\%) & \\
\hline Age, y & $71.9(7.8)$ & $72.4(8.8)$ & $78.2(7.9)$ & $75.7(8.6)$ & $P<0.001$ \\
\hline Education, y & $11.9(4.6)$ & $10.8(4.4)$ & $9.3(4.7)$ & $10.3(4.7)$ & $P<0.001$ \\
\hline MMSE & $28.1(1.9)$ & $26.1(2.5)$ & $18.3(5.7)$ & $22.0(6.4)$ & $P<0.001$ \\
\hline$A D L$ & $0.1(0.4)$ & $0.3(0.9)$ & $3.2(4.8)$ & $2.4(4.3)$ & $P<0.001$ \\
\hline NPI-Q & $2.1(2.9)$ & $2.6(3.8)$ & $6.8(6.7)$ & $5.6(6.3)$ & $P<0.001$ \\
\hline \multicolumn{6}{|l|}{ CDR } \\
\hline 0 & 365 (100\%) & - & - & $365(21.9 \%)$ & $P<0.001$ \\
\hline 0.5 & - & $338(100 \%)$ & 180 (18.6\%) & $518(31.0 \%)$ & \\
\hline 1 & - & - & 567 (58.7\%) & 567 (34.0\%) & \\
\hline 2 & - & - & 177 (18.3\%) & 177 (10.6\%) & \\
\hline 3 & - & - & $42(4.3 \%)$ & $42(2.5 \%)$ & \\
\hline \multicolumn{6}{|l|}{ APOE } \\
\hline E2E2 & $4(1.1 \%)$ & $3(0.9 \%)$ & $3(0.3 \%)$ & $10(0.6 \%)$ & $P<0.001$ \\
\hline E2E3 & $51(14.1 \%)$ & $37(11.0 \%)$ & $88(9.0 \%)$ & 176 (10.5\%) & \\
\hline E2E4 & $11(3.0 \%)$ & $5(1.5 \%)$ & $24(2.5 \%)$ & $40(2.4 \%)$ & \\
\hline E3E3 & $240(66.3 \%)$ & $223(66.0 \%)$ & 518 (53.2\%) & 981 (58.6\%) & \\
\hline E3E4 & 52 (14.4\%) & 59 (17.5\%) & 306 (31.5\%) & 417 (24.9\%) & \\
\hline E4E4 & $4(1.1 \%)$ & $11(3.3 \%)$ & $34(3.5 \%)$ & $49(2.9 \%)$ & \\
\hline \multicolumn{6}{|l|}{ Diseases } \\
\hline CV diseases & $60(19.1)$ & $81(24.5 \%)$ & 218 (22.2\%) & 359 (22.1\%) & $P=0.25$ \\
\hline Stroke & $8(2.5 \%)$ & $14(4.2 \%)$ & $46(4.7 \%)$ & $68(4.2 \%)$ & $P=0.26$ \\
\hline Hypertension & $183(58.3 \%)$ & 174 (52.6\%) & $586(60.0 \%)$ & $943(58.1 \%)$ & $P=0.06$ \\
\hline Dyslipidemia & 69 (22.1\%) & 79 (24.2\%) & $213(22.0 \%)$ & 361 (22.5\%) & $P=0.69$ \\
\hline Diabetes & 69 (22.0\%) & $71(21.5 \%)$ & $266(27.3 \%)$ & $406(25.1 \%)$ & $P=0.04$ \\
\hline
\end{tabular}




\begin{tabular}{|c|c|c|c|c|c|}
\hline Mortality & $21(5.8 \%)$ & $22(6.5 \%)$ & $248(25.2 \%)$ & $291(17.2 \%)$ & $P<0.001$ \\
\hline CNS & $1(0.3 \%)$ & 0 & 15 (1.5\%) & 16 (0.9\%) & \\
\hline Cancer & $5(1.4 \%)$ & $8(2.4 \%)$ & 47 (4.8\%) & $60(3.6 \%)$ & \\
\hline CV disease & $5(1.4 \%)$ & $2(0.6 \%)$ & $59(6.0 \%)$ & 66 (3.9\%) & \\
\hline Respiratory & $2(0.5 \%)$ & $4(1.2 \%)$ & $47(4.8 \%)$ & $53(3.1 \%)$ & \\
\hline Others & $8(2.2 \%)$ & $8(2.4 \%)$ & $80(8.1 \%)$ & $96(5.7 \%)$ & \\
\hline
\end{tabular}

Abbreviations: MCl: mild cognitive impairment; AD: Alzheimer disease; MMSE: Mini-Mental State Examination; ADL: activities of daily living; NPI-Q: Neuropsychiatric Inventory Questionnaire; CDR: Clinical Dementia Rating; CV: cardiovascular; CNS: central nervous system

Table 2 Cox regression models investigating cognitive diagnosis and neuropsychiatric symptoms predicting mortality 


\begin{tabular}{|c|c|c|c|c|}
\hline & B (SE) & Wald & Significance & $\mathrm{HR}(95 \% \mathrm{Cl})$ \\
\hline \multicolumn{5}{|c|}{ Model I (for cognitive diagnosis) } \\
\hline Diagnosis & & 10.95 & 0.004 & \\
\hline Control & & & & 1 \\
\hline $\mathrm{MCl}$ & $0.15(0.34)$ & 0.20 & 0.66 & $1.16(0.60-2.24)$ \\
\hline$A D$ & $0.76(0.27)$ & 7.85 & 0.005 & $2.14(1.26-3.64)$ \\
\hline \multicolumn{5}{|c|}{ Model II (for diagnosis and NPS) } \\
\hline Diagnosis/NPS & & 22.29 & 0.001 & \\
\hline Control & & & & 1 \\
\hline MCl/NPS - & $-0.29(0.43)$ & 0.46 & 0.50 & $0.75(0.33-1.73)$ \\
\hline $\mathrm{MCl} / \mathrm{NPS}+$ & $0.84(0.40)$ & 4.44 & 0.035 & $2.30(1.06-5.01)$ \\
\hline AD/NPS - & $0.55(0.29)$ & 3.72 & 0.05 & $1.74(1.00-3.04)$ \\
\hline AD/NPS + & $0.95(0.28)$ & 11.50 & 0.001 & $2.58(1.49-4.46)$ \\
\hline \multicolumn{5}{|c|}{ Model III (for diagnosis and domains of NPS) } \\
\hline Diagnosis/mood & & 16.05 & 0.003 & \\
\hline Control & & & & 1 \\
\hline $\mathrm{MCl} / \operatorname{mood}$ - & $0.04(0.84)$ & 0.002 & 0.96 & $1.04(0.20-5.44)$ \\
\hline $\mathrm{MCl} / \mathrm{mood}+$ & $1.10(0.55)$ & 3.97 & 0.046 & $3.00(1.02-8.83)$ \\
\hline$A D /$ mood - & $0.86(0.31)$ & 7.74 & 0.005 & $2.37(1.29-4.36)$ \\
\hline $\mathrm{AD} / \mathrm{mood}+$ & $1.00(0.29)$ & 11.93 & 0.001 & $2.72(1.54-4.79)$ \\
\hline Diagnosis/psychosis & & 1.90 & 0.39 & \\
\hline Diagnosis/frontal & & 3.17 & 0.21 & \\
\hline
\end{tabular}

Controlled for age, sex, education, Mini-Mental State Examination, activities of daily living, and medical diseases (cardiovascular disease, stroke, hypertension, diabetes, and dyslipidemia)

HR: hazard ratio; $\mathrm{Cl}$ : confidence interval; $\mathrm{MCl}$ : mild cognitive impairment; AD: Alzheimer disease; NPS: neuropsychiatric symptoms

\section{Figures}




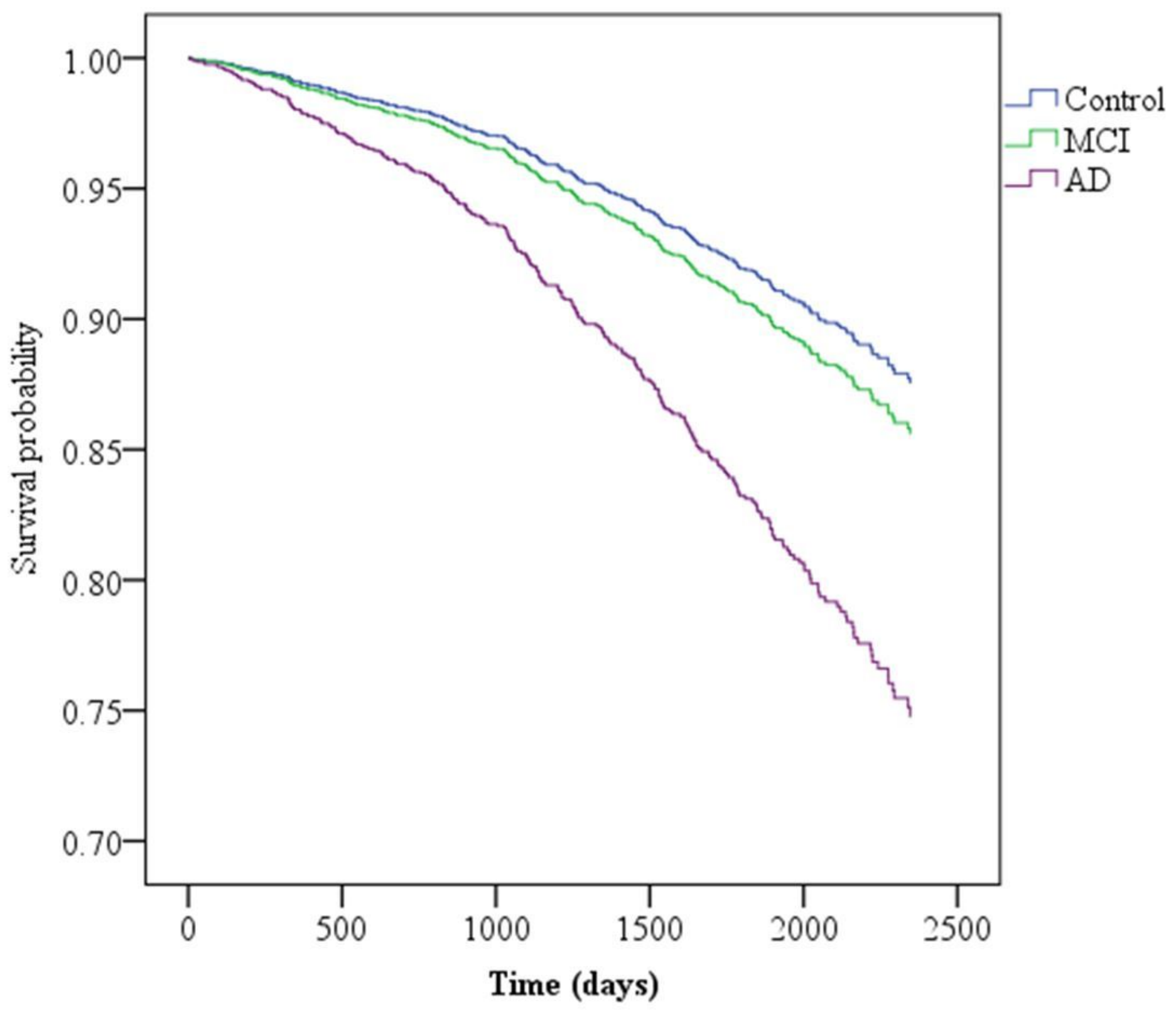

Figure 1

Survival curves for people with dementia due to Alzheimer's disease(AD) and mild cognitive impairment $(\mathrm{MCl})$ 


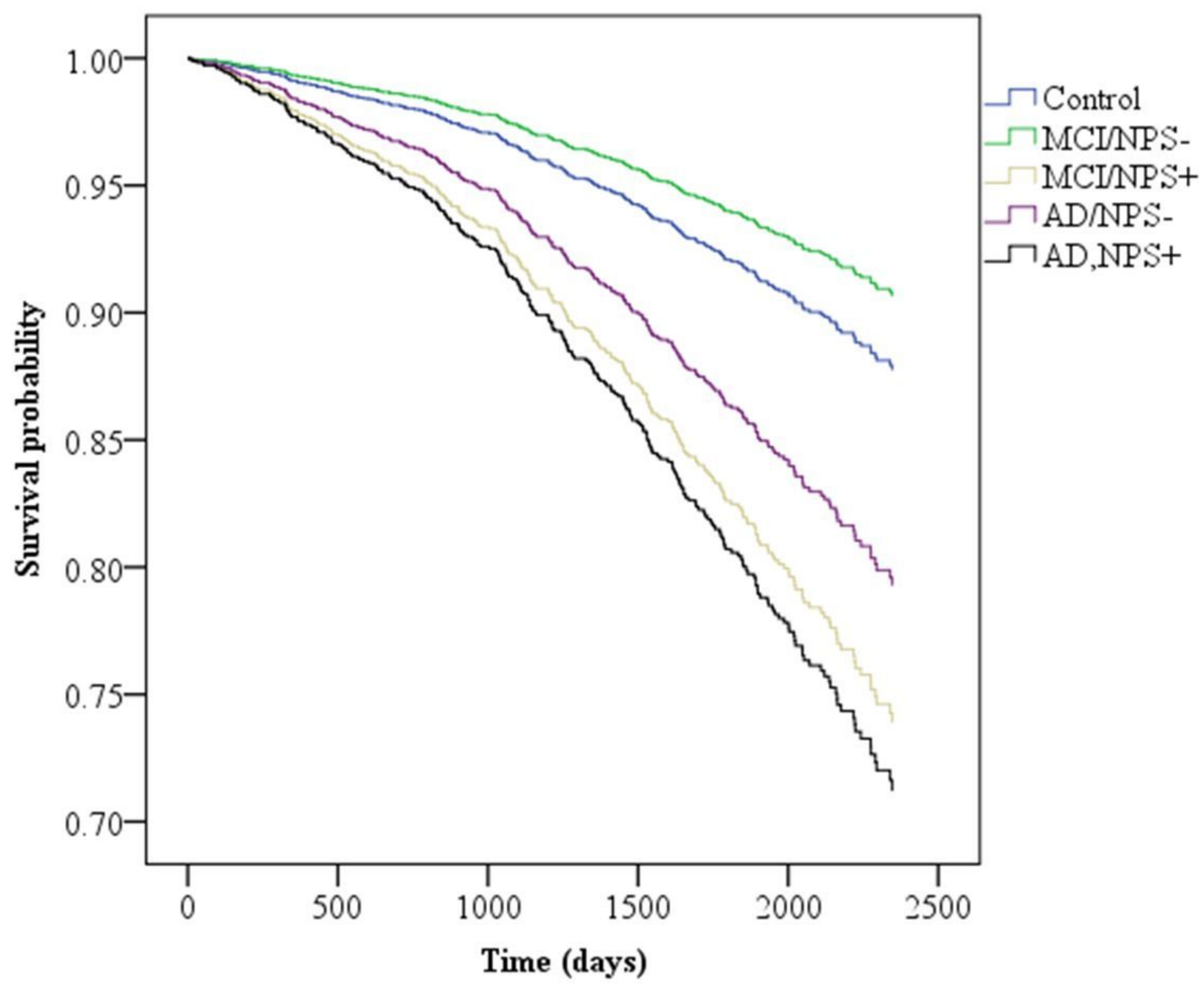

Figure 2

Survival curves for neuropsychiatric symptoms(NPS) among people with Alzheimer's disease(AD) and mild cognitive impairment $(\mathrm{MCl})$ 